\title{
Incidence of shoulder dystocia and its relation to brachial plexus palsy: a 10 year retrospective review at King Abdulaziz University Hospital
}

\author{
Ayman A. Bukhari ${ }^{1 *}$, Osama S. Bajouh ${ }^{1}$, Dania M. Bresali ${ }^{2}$, Alaa A. Roblah ${ }^{2}$, Zahraa I. \\ Alghafli ${ }^{2}$, Dareen A. Khawjah', Bushra K. Alhawsa ${ }^{2}$
}

\footnotetext{
${ }^{1}$ Department of Obstetrics and Gynecology, Faculty of Medicine, King Abdulaziz University, Jeddah, Saudi Arabia

${ }^{2}$ Medical Student ( $6^{\text {th }}$ Year), King Abdulaziz University, Jeddah, Saudi Arabia
}

Received: 09 October 2016

Revised: 10 October 2016

Accepted: 03 November 2016

\author{
*Correspondence: \\ Dr. Ayman A. Bukhari, \\ E-mail: bukhari84@hotmail.com
}

Copyright: ( $)$ the author(s), publisher and licensee Medip Academy. This is an open-access article distributed under the terms of the Creative Commons Attribution Non-Commercial License, which permits unrestricted non-commercial use, distribution, and reproduction in any medium, provided the original work is properly cited.

\begin{abstract}
Background: Objective of the study was to determine the incidence of shoulder dystocia (SD) in King Abdulaziz University Hospital (KAUH), with a focus on Brachial Plexus Palsy (BPP) and the accompanying risk factors.

Methods: We conducted a retrospective study of all vaginal deliveries between 2005 and 2014. Out of 29,199 vaginal deliveries, 236 cases where diagnosed with SD at KAUH in Jeddah, KSA. The following maternal and perinatal variables were reviewed by the patients' medical records: (booking status, maternal age, gestational age, maternal Body Mass Index (BMI), presence of diabetes, previous history of SD, instrumental delivery, Birth weight, Erb's and Klumpke's palsies).

Results: A total of 236 cases had SD with an incidence of (0.8\%). Only 55 cases among all had BPP. The Erb's palsy was found in 54 cases $(30.7 \%)$ while Klumpke's palsy was found only in one case $(0.6 \%)$. There were $121(68.8 \%)$ cases with no BPP and a remaining of 60 unknown BPP outcomes. From the total number of cases with SD, mothers with overweight and obesity were found in $93 \%$ of the cases.

Conclusions: Most of clinically diagnosed SD cases did not give the consequence of BPP. However, this complication in addition to other complications of SD mandates extra caution in cases with risk factors.
\end{abstract}

Keywords: Brachial plexus palsy, Erb's palsy, Shoulder dystocia

\section{INTRODUCTION}

Shoulder dystocia (SD) is an Obstetric complication of vaginal deliveries requiring additional obstetric maneuvers. It occurs due to traction of one or both shoulders against the bones of the maternal pelvis. ${ }^{1}$ The incidence of SD is generally estimated to be 0.6-1.4\% and $0.58-0.70 \%$ according to the American College of Obstetricians and Gynecologists (ACOG) and the Royal College of Obstetricians and Gynecologists (RCOG) respectively. Several risk factors leading to SD include maternal diabetes, prolonged labor, obesity, operative vaginal delivery, previous shoulder dystocia and fetal macrosomia., ${ }^{2,3}$ Multiple studies are conducted looking for the most prominent risk factors among all. Fetal macrosomia was found to be one of the most prominent risks leading to SD. ${ }^{2,3}$ However, it is still difficult to find reliable and dependable risk factors that mandate the occurrence of SD. ${ }^{2,3}$ Adverse neonatal outcomes and maternal harm are increased in the incident of SD. Proper management with different maneuvers such as McRobert's maneuver, suprapubic pressure, rotational maneuvers, and delivery of the posterior arm is important to avoid complications. ${ }^{1}$ A very serious fetal complication with variant incidence is brachial plexus palsy. ${ }^{5-7}$ Injury to $\mathrm{C} 5$ and $\mathrm{C} 6$ nerve roots, resulting in the clinical findings of Erb-Duchenne palsy, and fewer to that is an injury of the (C7, C8 and T1) nerve roots leading to Klumpke's Palsy. 
The aim of our study is to determine the incidence of SD in our tertiary center and to detect the predicting risk factors in our society taking in consideration the outcome of BPP.

\section{METHODS}

Ethical approval was obtained from the unit of biomedical ethics At KAUH which is a tertiary center in Jeddah-KSA. A total number of 41,546 deliveries were taken from the labor and delivery annual records. Of those, 29,199 had vaginal deliveries. Afterwards, identification of 236 cases of SD was manually verified from the documentation in the hospital annual records from the first of July 2005 until the 30th of December 2014. Then, a retrospective review of the maternal and neonatal medical paper records of all subjects was obtained and data were collected manually on specifically designed collection sheets. A computerized database was also used to confirm the findings. The following maternal and labor variables were reviewed as inclusion criteria: (maternal booking status, presence of diabetes both frank and gestational diabetes mellitus (GDM), neonatal weight, brachial plexus palsy-Erb's or klump's palsy and the mode of delivery). These variables were analyzed as factors affecting the outcome of SD. Exclusion criteria included multiple fetuses and cesarean section deliveries. Statistical Package for Social Sciences (SPSS) software Version16.0 was used to analyze the data.

\section{RESULTS}

Of total number of vaginal deliveries during study period, 236 cases where diagnosed with SD at KAUH. Therefore, the hospital-based incidence of SD in Jeddah was $0.8 \%$. In this study period, 55 neonates $(31 \%)$ had BPP while 121 neonates $(69 \%)$ did not have BPP. The rate of Erb's and Klumpke's palsy was found to be 54cases $(30.7 \%)$ and one case $(0.6 \%)$, respectively. The remaining 60 cases had no documentation about BPP status in the neonate (Figure 1).

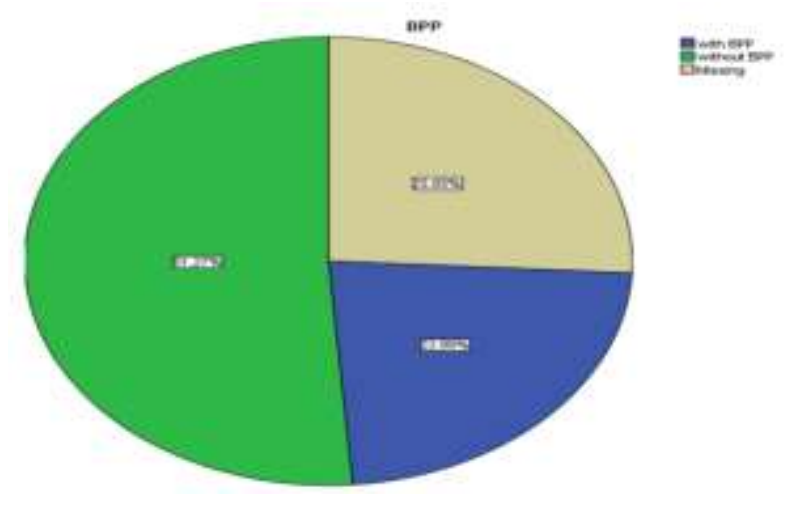

Figure 1: Percentages of brachial plexus palsy cases in the neonate.
Socio-demographic and antenatal characteristics of SD cases are shown in Table 1. Risk factors of SD are demonstrated in Table 2.

Table 1: Socio-demographic and antenatal characteristics of shoulder dystocia cases, KAUH, 2005-2014.

\begin{tabular}{|ll|}
\hline Characteristic & $\mathbf{N}=236 \mathbf{N}(\%)$ \\
\hline BPP & \\
With BPP & $55(31)$ \\
Without BPP & $121(69)$ \\
\hline Age: & $3(1)$ \\
19 or less & $88(38)$ \\
$20-29$ & $112(48)$ \\
$30-39$ & $29(13)$ \\
40 or more & \\
\hline Booking status: & $127(56)$ \\
Booked & $99(44)$ \\
unbooked & \\
\hline Gestational age & $14(7)$ \\
36 or less & $93(44)$ \\
$37-39$ & $104(49)$ \\
40 or more & \\
\hline
\end{tabular}

Table 2: Risk factors of shoulder dystocia cases, KAUH, 2005-2014.

\begin{tabular}{|ll|}
\hline Charictaristic & $\mathrm{N}=236 \mathbf{N}(\%)$ \\
\hline Diabetic Mother & $38(16)$ \\
Not Diabetic mother & $198(84)$ \\
\hline BMI: & $7(7)$ \\
Normal weight less 25 & $32(31)$ \\
Overweight 25-30 & $63(62)$ \\
Obese Over 30 & \\
\hline Birth weight (Kg) & $132(66)$ \\
Normal 4.0 or less 4 & $48(24)$ \\
Macrosomia 4.1 to 4.5 & $20(10)$ \\
Over macrosomia 4.6 or more & \\
\hline Mode of delivery & $207(89)$ \\
SVD & $20(9)$ \\
Ventous & $4(2)$ \\
Forceps & $11(5)$ \\
\hline Previous history of SD & $209(95)$ \\
No Previous history of SD & \\
\hline
\end{tabular}

Percentage of mothers with high BMI over 25 among 102 cases was (93\%) and those with normal BMI were accounted only in $(7 \%)$. Cases with unknown BMI were 134 cases.

Diabetes including both gestational and frank diabetes was found in 38 cases (16\%) (Figure 2). Spontaneous vaginal Delivery was the predominant mode of delivery among all cases with 207 cases (89\%). Cases whom delivered by ventouse delivery were $20(9 \%)$ while forceps delivery was only in 4 cases (2\%). Mood of delivery was undocumented in 5 cases (Figure 3 ). 
There were $127(56 \%)$ booked ladies and $99(44 \%)$ unbooked ladies with 10 missing booking status. Table 3 shows that the years of 2009 have the highest number of SD cases $1.31 \%$ in comparison to all the years in the study period while 2006 have lowest number $0.41 \%$. Date of birth was unknown in 3 cases.

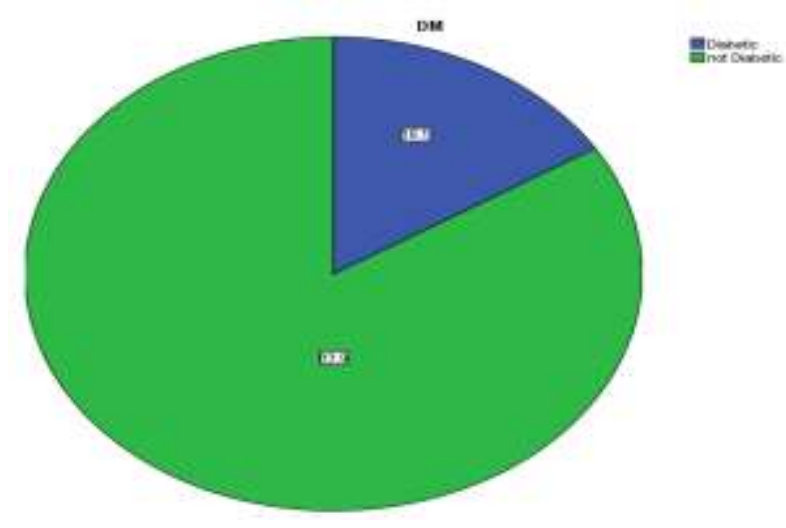

Figure 2: Percentage of diabetes among brachial plexus palsy cases.

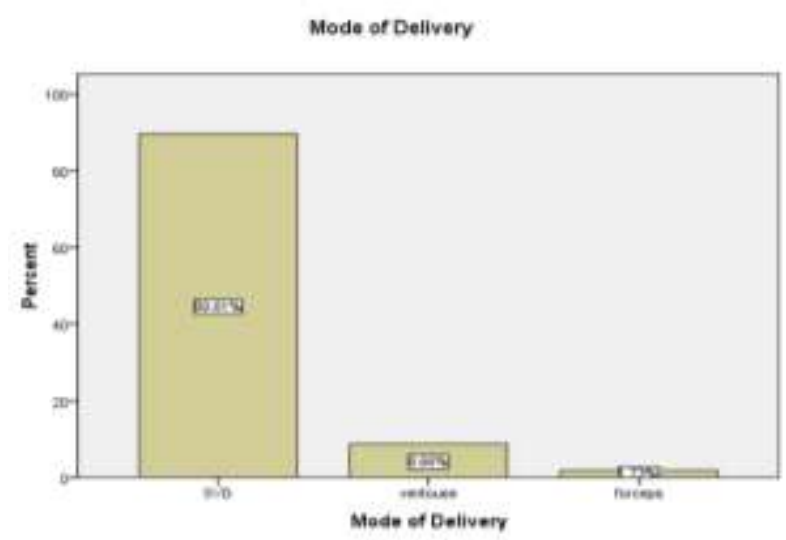

Figure 3: Mode of delivery among brachial plexus palsy cases.

Table 3: Incidence of SD.

\begin{tabular}{|lllll|}
\hline Year & $\begin{array}{l}\text { Total } \\
\text { delivery }\end{array}$ & $\begin{array}{l}\text { Total } \\
\text { VD }\end{array}$ & $\begin{array}{l}\text { Total } \\
\text { SD }\end{array}$ & $\begin{array}{l}\text { Incidences } \\
\%\end{array}$ \\
\hline 2014 & 3283 & 2153 & 16 & $0.74 \%$ \\
\hline 2013 & 4373 & 2984 & 19 & $0.64 \%$ \\
\hline 2012 & 4599 & 3239 & 22 & $0.68 \%$ \\
\hline 2011 & 4760 & 3288 & 23 & $0.76 \%$ \\
\hline 2010 & 4238 & 3035 & 23 & $0.76 \%$ \\
\hline 2009 & 4243 & 2744 & 36 & $1.31 \%$ \\
\hline 2008 & 4398 & 3315 & 35 & $1.06 \%$ \\
\hline 2007 & 3919 & 2917 & 20 & $0.69 \%$ \\
\hline 2006 & 3834 & 3440 & 14 & $0.41 \%$ \\
\hline 2005 & 3899 & 3084 & 25 & $0.81 \%$ \\
\hline Total & 41546 & 29199 & 233 & $0.77 \%$ \\
\hline
\end{tabular}

\section{DISCUSSION}

In the study, we calculated the incidence of SD in our tertiary center-KAUH. There were a total of 41546 deliveries in the years from 2005-2014 including both vaginal deliveries and caesarian sections. A total of 236 cases of SD where found out of 29,199 vaginal deliveries in percentage of $0.8 \%$ which is in the range of the studies that we compared our research with. One of them is Alexandra Hansen study who found the incidence of SD from 28 different articles to be $0.7 \%$. $^{9}$ They measured that incidence throughout the years out of 2,575,283 vaginal births with 18,222 diagnosed cases with SD. In our records, we found that the incidence of SD on 2009 was $1.3 \%$ which is the highest among the years and the incidence on 2006 was $0.4 \%$ which is the lowest throughout the years in the study period (Table 3 shows the incidence of SD per a year). In regards to Erb's palsy, we identified 54 cases $30.7 \%$ out of the total number of $\mathrm{SD}$ cases. On the other hand, a study of $\mathrm{K}$ Weizsaecker which was done in USA and correlated the incidence of Erb's palsy with the incidence of SD, all the cases of Erb's palsy were taken retrospectively and found that $67 \%$ cases were associated with the earlier diagnosis of SD. ${ }^{3}$ Similar to our results regarding diabetes is a retrospective study of Joseph G in Los Angeles with 221 case of SD during the period of August 1995 to February 2004, 45 cases $20.4 \%$ of women had diabetes. ${ }^{10}$ In A study conducted in Oman among 111 cases with shoulder dystocia and 111 controls, during 1994-2006 diabetes mellitus was found in 40 cases of SD $36 \%$ which was higher than our results. ${ }^{11}$ Taking maternal weight as a risk factor, the former study had similar results to our study where normal maternal weight was found in 11cases (10\%) only. Overweight was in 28 case $(25 \%)$ and obesity in 72 case $(65 \%){ }^{11}$

Operative vaginal delivery was found in a higher rate than what we found in other studies including one retrospective cohort study by $\mathrm{T}$. Burkhardt that calculated $34.3 \%$ operative vaginal deliveries in a period from January 1995 to June $2011 .^{12}$ From the cases of SD, a case control study in National Maternity Hospital found identified 12 cases $(18 \%)$ of operative vaginal delivery in a total of 66 cases. ${ }^{13}$

\section{Limitations}

Our SD cases were collected from patients' medical records; there were a lot of missing information from either maternal or neonatal files leading to the exclusion of those cases.

Furthermore, our study was exclusive to our hospital and not a multi centric one, so we could not be able to reflect our results on the whole population of Saudi Arabia nor Jeddah city. 


\section{CONCLUSION}

Most of clinically diagnosed SD cases did not give the consequence of BPP. However, this complication in addition to other complications of SD mandates extra caution in cases with risk factors. We recommend that all personnel dealing with women in labor should be satisfactorily skilled and continuously trained to predict and deal with this obstetrical obstacle.

Funding: No funding sources Conflict of interest: None declared

Ethical approval: The study was approved by the Institutional Ethics Committee

\section{REFERENCES}

1. Spain JE, Frey HA, Tuuli MG. Neonatal morbidity associated with shoulder dystocia maneuvers. Am J Obstet Gynecol. 2015;212:353.e1-5.

2. Gherman RB, Chauhan S, Ouzounian JG, Lerner H, Gonik B, Goodwin TM. Shoulder dystocia: The unpreventable obstetric emergency with empiric management guidelines. Am J Obstet Gynecol. 2006;195:657-72.

3. Weizsaecker K, Deaver J, Cohen W. Labour characteristics and neonatal Erb's palsy. BJOG 2007; 114:1003-1009.

4. Weissmann-Brenner A, Simchen MJ, Zilberberg E, Kalter A, Weisz B, Achiron R, et al. Maternal and neonatal outcomes of macrosomic Pregnancies. Med Sci Monit, 2012;18(9):PH77-81.

5. ACOG Committee on Practice BulletinsGynecology, the American College of Obstetrician and Gynecologists. ACOG practice bulletin clinical management guidelines for obstetriciangynecologists. Obstet Gynecol. 2002;100(5 Pt 1):1045-50.
6. Rahman J, Bhattee G, Rahman MS. Shoulder dystocia in a 16-year experience in a teaching hospital. J Reprod Med. 2009;54(6):378-84.

7. Iskender C, Kaymak O, Erkenekli K, Ustunyurt E, Uygur D. Neonatal Injury at Cephalic Vaginal Delivery: A Retrospective Analysis of Extent of Association with Shoulder Dystocia. PLoS ONE. 2014;9:e104765.

8. Mir S, Ahmad A. Shoulder Dystocia. JK Science. 2010;12:165-7.

9. Hansen A, Chauhan SP. Shoulder dystocia: Definitions and incidence. Seminars in per Inatology. 2014;38:184-8.

10. Ouzounian JG, Korst LM, Miller DA, Lee RH. Brachial Plexus Palsy and Shoulder Dystocia: Obstetric Risk Factors Remain Elusive. Am J Perinatol. 2013;30:303-8.

11. Al-Khaduri MM, Abudraz RM, Rizvi SG, Al-Farsi YM. Risk Factors Profile of Shoulder Dystocia in Oman: A Case Control Study. Oman Med J. 2014;29(5):325-9.

12. Burkhardt T, Schmidt M, Kurmanavicius J, Zimmermann R, Schaffer L. Evaluation of fetal anthropometric measures to predict the risk for shoulder dystocia. Ultrasound Obstet Gynecol. 2014;43:77-82.

13. Geary M, McParland P, Johnson H, Stronge J. Shoulder dystocia- is it predictable? Eur J of Obs and Gyne and Rep Bio. 1995;62:15-8.

Cite this article as: Bukhari AA, Bajouh OS, Bresali DM, Roblah AA, Alghafli ZI, Khawjah DA, et al. Incidence of shoulder dystocia and its relation to brachial plexus palsy: a 10 year retrospective review at King Abdulaziz University Hospital. Int J Reprod Contracept Obstet Gynecol 2016;5:4415-8. 